\title{
Revisão sistemática de estudos sobre os aspectos escolares relacionados ao cometimento de delitos
}

Systematic review of studies addressing school aspects related to the committing of offenses

Revisión sistemática de estudios acerca de los aspectos escolares relacionados con la comisión de delitos

\author{
Jorge Luiz da Silva* \\ Marina Rezende Bazon ${ }^{* *}$
}

\begin{abstract}
Resumo
Trata-se de uma revisão sistemática da literatura nacional e internacional norteada pelo objetivo de investigar a relação entre escolarização e conduta infracional na adolescência. Foram consultadas duas bases de dados (Web of Science e LILACS) e a biblioteca Scielo, no período de 2009 a 2013. Os resultados oriundos da análise dos 25 artigos recuperados foram sintetizados em cinco categorias temáticas e evidenciaram a complexidade da interface existente entre os temas investigados, denotando a existência de uma natureza sequencial e complementar entre as trajetórias de desenvolvimento pessoal, social e escolar relacionadas à conduta infracional. Como ficou evidenciado que uma experiência escolar negativa se configura como um marco importante para a entrada ou para o agravamento da conduta delituosa na adolescência. Ressalta-se a necessidade de realização de mais estudos no contexto nacional, em razão da escassez de produções desenvolvidas acerca dessa temática no contexto sociocultural brasileiro.
\end{abstract}

Palavras-chave: Adolescente em conflito com a lei. Educação. Escola. Revisão de literatura.

\footnotetext{
Abstract

This is a systematic review of national and international literature to investigate the relationship between schooling and the committing offenses during adolescence. Two databases were consulted (Web of Science and LILACS) and the Scielo library between 2009 and 2013. The

Texto recebido em abril 2014 e aprovado para publicação em janeiro de 2015.

Fundação de Amparo à Pesquisa do Estado de São Paulo. Processo n. ${ }^{\circ}$ 2011/04634-9

Doutorando em Enfermagem em Saúde Pública pela Universidade de São Paulo (USP). Endereço: Avenida Bandeirantes, 3900 Monte Alegre, Ribeirão Preto-SP, Brasil. CEP: 14040-901. E-mail: jorgelsilva@usp.br.

* Doutora em Psicologia pela Universidade de São Paulo (USP), mestrada en Science - Psychoéducation pela Université de Montreal, Canadá, graduada em Psicologia pela USP, membro associado pleno da Sociedade Brasileira de Psicologia e membro da International Society for Criminology, docente do Departamento de Psicologia da Faculdade de Filosofia, Ciências e Letras de Ribeirão Preto da Universidade de São Paulo (USP-RP), experiência em pesquisa e intervenção junto a grupos considerados em situação de risco psicossocial, especialmente crianças e adolescentes, atuando nos seguintes temas: crianças e adolescentes vitimizados e família, adolescentes em conflito com a Lei e intervenção psicossocial (psicoeducação)/avaliação de programas.
} E-mail: mbazon@ffclrp.usp.br 
analysis resulted in 25 papers, which were synthesized into five thematic categories and showed the complexity of the interface existing among the investigated themes, demonstrating a sequential and complementary nature for the trajectories of personal, social and school development related to committing offense. The results show that a negative school experience is an important mark for the entrance into or aggravation of criminal conduct during adolescence, thus showing the need for further studies in the national context given the scarcity of research addressing this subject in the Brazilian sociocultural context.

Keywords: Adolescents in conflict with the law. Education. School. Literature review.

\section{Resumen}

Se trata de una revisión sistemática de la literatura nacional e internacional guiada por el objetivo de investigar la relación entre la escolaridad y la conducta infraccional en la adolescencia. Fueron consultadas dos bases de datos (Web of Science y LILACS) y la Biblioteca Scielo fueran consultadas en el período 2009-2013. Los resultados obtenidos a partir del análisis de 25 artículos recuperados fueron sintetizados en cinco categorías temáticas y evidenciaron la complejidad de la interacción entre los temas de investigación, lo que denota la existencia de una naturaleza secuencial y complementaria entre las trayectorias de desarrollo personal, social y escolar relacionadas con la conducta infraccional. Como se demostró que una experiencia escolar negativa se configura como una un marco importante para la entrada o para el agravamiento de la conducta delictiva en la adolescencia, se pone de relieve la necesidad de realizar más investigaciones en el contexto nacional, debido a la escasez de producciones desarrolladas en este tema en el contexto sociocultural brasileño.

Palabras clave: Adolescente en conflicto con la ley. Educación. Escuela. Revisión de literatura.

\section{Introdução}

envolvimento de adolescentes com a prática de atos infracionais é considerado, atualmente, em muitas sociedades, um importante problema social. Além de gerar gastos públicos com o Sistema de Segurança e de Justiça Juvenil, bem como prejuízos econômicos e psicossociais às vítimas e à sociedade em geral (LeBlanc, 2003; Maschia, Hatcher, Schwalbe \& Rosato, 2008; Ward et al., 2010), a atividade infracional na adolescência implica, muitas vezes, em experiências negativas e na exposição dos jovens infratores a situações de risco, que podem impactar e comprometer seu desenvolvimento psicossocial (Hirschfield, 2009). 
A prática de infrações pode ser um gesto ocasional na adolescência, associado ao teste de limites próprio da idade e por esta não representar um problema desenvolvimental significativo. Todavia, quando a prática de infrações é repetitiva, apesar de intervençóes jurídicas e sociais, esta representa um problema desenvolvimental, geralmente associado a uma ampla gama de variáveis biológicas, psicológicas e sociais que interagem sinergicamente, da infância à adolescência, de modo a produzir e sustentar a conduta ao longo do tempo. Algumas das variáveis sublinhadas pela literatura são: baixa condição socioeconômica da família, disfunção familiar, vitimização doméstica, histórico de abuso, passagem por serviços de proteção, problemas de saúde mental, consumo de substâncias psicoativas e insucesso escolar (Bazon, Komatsu, Panosso \& Estevão, 2011; LeBlanc, 2006; Zhang, 2011).

$\mathrm{Na}$ contramão dessas variáveis, oferecendo uma barreira aos seus efeitos adversos, fatores protetivos ao engajamento de adolescentes com a prática de atos infracionais também são destacados nas investigaçôes especializadas, sendo que uma "experiência de escolarização assinalada por sucessos e aspectos positivos" tem sido considerada uma das variáveis protetivas de maior peso (Janosz \& LeBlanc, 1999; Liljeberg, Eklund, Fritz \& Klinteberg, 2011).

Quando se assume que a escola influencia significativamente a conduta do aluno, por meio de sua organização, clima institucional e práticas, podese pressupor que os aspectos envolvidos nessa dinâmica são relevantes para elucidar as relações que melhor predizem a (des)adaptação dos alunos. Nessa linha, alguns estudos apontam aspectos da vivência escolar mais fortemente associados à conduta infracional: baixo desempenho, relação conflituosa com pares e professores e punições escolares reiteradas e severas (Ashkar \& Kenny, 2009; Sullivan, Dollard, Sellers \& Mayo, 2010; Wynne \& Joo, 2011).

Em termos dinâmicos, um baixo desempenho concorre para o enfraquecimento do vínculo escolar, mediante o aumento de sentimentos de rejeição e exclusão, decorrentes da frustração em relação à própria capacidade para a aprendizagem. A qualidade das relaçôes entre o aluno e os professores e entre o aluno e seus pares também é importante para a vinculação à escola e, quando ruim, tem efeito negativo sobre o desempenho e o comportamento social. Com isso, têmse incrementadas as chances de ser sancionado/punido, em virtude das regras escolares, o que, por sua vez, fragiliza ainda mais a vinculação (LeBlanc, 2003).

É provável também que, para determinados alunos, a escola represente um contexto de aprendizagem de comportamentos de desobediência às normas de convivência social e de comportamentos infracionais, devido à socialização entre pares (estudantes) (Frías-Armenta, López-Escobar \& Díaz-Méndez, 2003). Além 
disso, sendo a formação escolar muito importante para a ascensão profissional e social, se o sucesso na escolarização constituir uma incerteza, os adolescentes podem sentir-se poucos motivados a adiarem gratificações de ocorrência mais imediata, em detrimento de benefícios futuros, o que abre caminho para a desistência dos estudos e isso, por sua vez, abre brechas para o trabalho precoce e, ou, para o envolvimento infracional (Caldwell, Wiebe \& Cleveland, 2006).

É importante sublinhar que esses apontamentos estão em consonância às argumentações que defendem que tanto a prevenção como o tratamento efetivo do problema relativo ao envolvimento de jovens com a prática de atos infracionais requerem ações que qualifiquem o processo de socialização dos adolescentes e que promovam seu desenvolvimento pessoal e social, contrariamente às argumentações que pleiteiam respostas de natureza repressiva e, ou, punitiva, baseadas essencialmente em medidas de restrição de liberdade, as quais, além de serem muito mais dispendiosas, não necessariamente desencorajam a prática de delitos (Silveira, Maruschi \& Bazon, 2012).

Dados recentes acerca da escolarização dos adolescentes em conflito com a lei em privação de liberdade, no contexto brasileiro, chamam a atenção quando denotam as dificuldades que parecem perpassar o processo de escolarização desses jovens. Por exemplo, $8 \%$ dos adolescentes submetidos à medida socioeducativa de internação devido à prática de delitos, no Brasil, não são alfabetizados. Considerando a média de idade do grupo, de aproximadamente 17 anos, e a série escolar em que se encontra a maioria, o $7^{\circ}$ ano do ensino fundamental, nota-se uma defasagem idade/série média de cerca de 4 a 5 anos. No mais, sabese que, no período anterior à internação, 57\% se encontravam evadidos da escola (Conselho Nacional de Justiça [CNJ], 2012).

Diante disso, são justificáveis os esforços que se envidarem no sentido de conhecer em detalhes e profundamente as variáveis atinentes à educação escolar que se encontram associadas ao comportamento infracional na adolescência e o modo como essas variáveis se articulam e parecem produzir seus efeitos. Assim, o objetivo deste estudo foi o de identificar, por meio de uma revisão sistemática da literatura, as variáveis escolares mais fortemente associadas à conduta infracional em adolescentes e descrever as relações entre essas variáveis e o problema em foco.

\section{Método}

Empregou-se a técnica da revisão sistemática de literatura. A busca bibliográfica foi realizada em uma base de dados internacional e multidisciplinar (a Web of Science), em uma base que abrange produções em Ciências da Saúde, 
especialmente na América Latina e Caribe (LILACS), e em uma biblioteca multidisciplinar nacional (Scielo).

Para a busca na base Web of Science, realizaram-se os seguintes cruzamentos de palavras-chave: juvenile delinquency and school, juvenile delinquency and education. Na base LILACS e biblioteca Scielo, os cruzamentos realizados foram: delinquência juvenil e escola; delinquência juvenil e educação; adolescente em conflito com a lei e escola; adolescente em conflito com a lei e educação; adolescente infrator e escola; adolescente infrator e educação. A maior variedade de palavras-chave nas buscas nestas duas bases de dados ocorreu em função de se saber previamente que as produções latino-americanas e nacionais utilizam com conotação semelhante os termos delinquência juvenil, adolescente infrator e adolescente em conflito com a lei.

As publicações resultantes do procedimento de busca foram selecionadas mediante leitura dos seus respectivos títulos e resumos, tendo sido usados os seguintes critérios de inclusão:

a) tipo de trabalho: optou-se pela inclusão apenas de artigos (excluindo-se teses, dissertaçóes, livros e capítulos de livros), pelo fato de os artigos serem sempre submetidos a um processo rigoroso de avaliação por pares, $o$ que lhes confere maior qualificação;

b) tempo: selecionaram-se estudos publicados entre os anos de 2009 e 2013, últimos cinco anos, pelo fato de se visar à produção recente, considerando-se que esta se assenta sobre o acúmulo do conhecimento já produzido;

c) língua: incluíram-se todas as produções disponibilizadas nas línguas portuguesa, inglesa e espanhola, pelo fato de se ter o domínio dessas três línguas;

d) temas: todos os trabalhos que tratassem diretamente a relação escola/escolarização e conduta infracional. Considerou-se que publicações seriam excluídas se seu conteúdo tratasse apenas secundariamente das questôes em foco, enfatizando mais propriamente outros assuntos.

Posteriormente, o conteúdo integral dos textos selecionados foi sintetizado numa tabela, contemplando os seguintes itens: título, autores, ano de publicação, título do periódico, país no qual a pesquisa foi desenvolvida, instituição de vinculação dos autores, objetivos dos estudos, metodologia, principais resultados e conclusóes. Tais dados serviram de respaldo tanto para análises descritivas, relativa à caracterização da produção científica, quanto para a análise crítica dos artigos revisados, referente ao conteúdo das publicações. 


\section{Resultados}

Na base de dados Web of Science, os cruzamentos das palavras-chave resultaram em 224 resultados, dos quais 24 foram selecionados e recuperados. A base LILACS, cuja abrangência contempla a América Latina e o Caribe, ofereceu menor quantidade de resultados, totalizando cinco publicações, das quais uma foi selecionada e recuperada. Não se obteve resultado na biblioteca Scielo com o cruzamento das palavras-chave supracitadas. A figura 1 apresenta o fluxograma de busca e seleção das produções identificadas.

Figura 1. Fluxograma do processo de seleção dos artigos
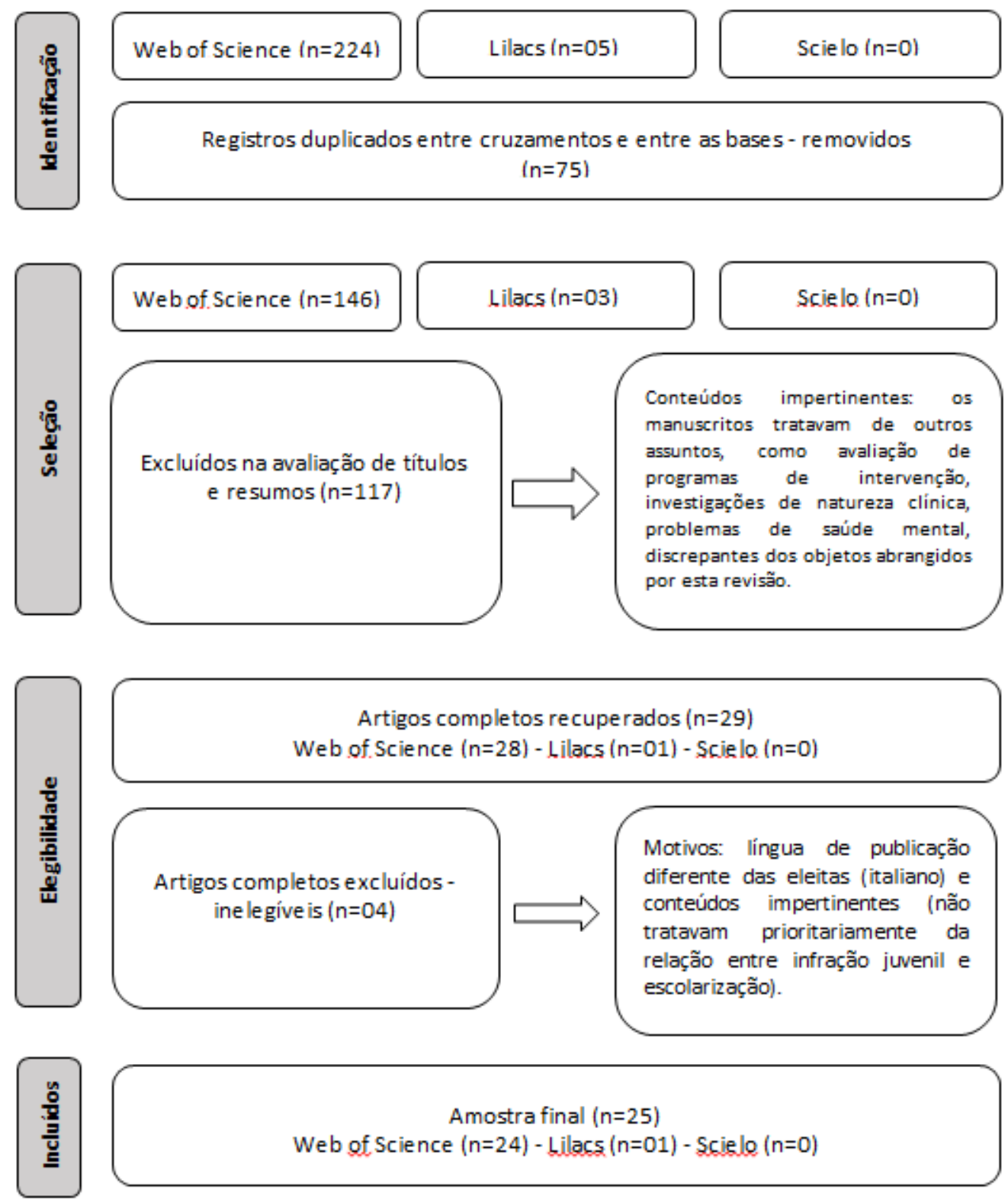

Fonte: elaborado pelos autores. 
Em relação ao ano dos artigos recuperados, observou-se que o volume de publicaçôes foi quase o mesmo em todo o período pesquisado, em conformidade à seguinte distribuição: $2009(\mathrm{n}=5), 2010(\mathrm{n}=7), 2011(\mathrm{n}=4), 2012(\mathrm{n}=4), 2013$ $(\mathrm{n}=5)$. A maioria das pesquisas foi realizada nos Estados Unidos $(\mathrm{n}=16)$. Outros países tiveram participação menor: Austrália $(\mathrm{n}=1)$, Bélgica $(\mathrm{n}=1)$, Brasil $(\mathrm{n}=1)$, Canadá $(n=1)$, Cingapura $(n=1)$, Coreia do Sul $(n=1)$, Hong Kong $(n=1)$, Macau $(n=1)$ e Suíça $(n=1)$. O idioma prevalente foi o inglês $(n=24)$, seguido pelo português $(n=1)$.

Os periódicos nos quais os artigos foram publicados variaram no tocante às áreas do conhecimento às quais estavam vinculados: Criminologia $(\mathrm{n}=10)$, Psicologia $(n=7)$, Educação, $(n=4)$, Psiquiatria $(n=2)$, Ciências Sociais $(n=1)$ e Medicina $(n=1)$. No que tange aos aspectos metodológicos, identificou-se uma prevalência de estudos transversais $(\mathrm{n}=12)$. Outros delineamentos também foram localizados, sendo eles: longitudinal $(n=6)$, documental $(n=5)$ e estudo de caso $(n=2)$. Os estudos, em sua maioria, tiveram os dados analisados por meio de procedimentos quantitativos (emprego de testes estatísticos).

Em termos de conteúdo, os principais resultados oriundos das análises dos trabalhos selecionados foram sintetizados em cinco categorias: 1) a associação entre a qualidade das experiências familiares, a adaptação escolar e a conduta na adolescência; 2) o relacionamento com professores e colegas como variável de base à vinculação escolar e protetiva ao envolvimento com a prática de delitos; 3) as sançôes escolares como variável de base à desvinculação escolar e risco ao envolvimento com a prática infracional; 4) a associação entre bullying, problemas escolares e comportamento infracional na adolescência; 5) a evasão escolar e a conduta infracional. Os principais apontamentos feitos na literatura são apresentados a seguir, de acordo com a categoria encontrada.

1) Associação entre a qualidade das experiências familiares, a adaptação escolar e a conduta na adolescência

Bui (2009) identificou que, na família, a severidade da disciplina, a falta de carinho e de atenção dos pais e a exposição dos filhos a modelos de comportamento de desobediência às normas de convivência social e a modelos de comportamento de violação das leis constituem-se em condições desfavoráveis ao sucesso escolar, e isso, por seu turno, favorece o desenvolvimento de conduta antissocial na adolescência. Nessa mesma direção, Ward et al. (2010) também concluíram que estressores familiares, tais como separações, perda de um dos pais, conflitos, dificuldades econômicas, supervisão parental fraca, negligência, maus-tratos, concorrendo à necessidade de intervenção familiar por parte dos serviços de 
proteção, e recomposição familiar constituíam-se em variáveis mediadoras entre baixo desempenho escolar, evasão e prática de delitos na adolescência.

Huan, Ang e Lim (2010), em seu turno, apontam que a prisão do pai se constitui, igualmente, em uma influência indireta na vida escolar dos filhos, devido ao impacto que isso produz na renda familiar, que tende a diminuir, e na qualidade de supervisão dos filhos, que também tende a enfraquecer, assim como o auxílio e a cobrança quanto ao desempenho escolar. Em função do distanciamento físico da figura paterna, a prisão do pai também interfere, segundo esse estudo, no processo de vinculação social dos filhos, o que pode gerar neles dificuldades de socialização com outras figuras de autoridade, como professores, e também com pares, no contexto escolar.

Kim e Page (2013) identificaram que uma boa vinculação com os pais colabora para o desenvolvimento da regulação emocional nos filhos, o que, por sua vez, diminui a quantidade de problemas de adaptação escolar, especialmente aqueles de natureza disciplinar. Verificaram ainda que os alunos com regulação emocional em níveis mais rebaixados apresentaram maior quantidade de problemas comportamentais, risco de evasão e envolvimento infracional. $\mathrm{O}$ baixo envolvimento das famílias no processo de escolarização dos filhos é em seu turno uma característica destacada por Sander, Sharkey, Olivarri, Tanigawa e Mauseth (2010), no estudo qualitativo que realizaram junto a grupos de adolescentes infratores.

2) O relacionamento com professores e colegas como variável de base à vinculação escolar e protetiva ao envolvimento com a prática de delitos

Investigando a experiência escolar de adolescentes infratores, Sander et al. (2010) verificaram que eles acumulavam experiências negativas referentes ao relacionamento, no cotidiano das aulas, com o corpo docente, marcado por muitos atritos e desentendimentos. Sumariamente, os adolescentes haviam sido expostos pelos professores a situações vexatórias, com frequência. Os autores também sublinham a vontade expressa pelos jovens em estabelecer melhor relacionamento com colegas, no entanto indicam que estes se consideravam incapazes para isso, por sentirem não ter habilidades sociais suficientes.

Outro estudo com o objetivo de conhecer a percepção de adolescentes infratores sobre a escola foi desenvolvido por Ashkar e Kenny (2009). Eles verificaram que a maioria dos entrevistados não tinha motivação para continuar estudando, sendo que as relações insatisfatórias com os professores se destacaram como fator subjacente ao desinteresse. Experiências de exposição à violência escolar também se destacaram, sendo que quase todos os adolescentes indicaram já ter se envolvido em situações de bullying. 
Paralelamente, suas relações sociais na escola se caracterizariam pelo contato reduzido com colegas não infratores e pela busca de status perante pares infratores. Isso também contribuiria para o surgimento de problemas de adaptação e para o envolvimento em situações de violência, além de propiciar dificuldades de aprendizagem, baixa frequência, desrespeito para com as autoridades escolares e conflitos familiares.

3) As sanções escolares como variável de base à desvinculação escolar e risco ao envolvimento com a prática de delitos

De acordo com Sullivan et al. (2010), as políticas de tolerância zero, nos Estados Unidos, têm se expandido para comportamentos menos graves, enviando à Justiça muitos alunos necessitados, na realidade, de auxílio educacional e apoio emocional. Assim, eles são rotulados na escola como "problemáticos", sendo que o contato com o Sistema de Justiça agrava ainda mais a situação desfavorável em que se encontram, tornando-os mais propensos a se associarem a pares que também apresentam conflito com a lei. Resultados similares foram obtidos por Kirk e Sampson (2013), que identificaram as reaçōes institucionais (sanções escolares) aos alunos com passagem pelo Sistema de Justiça como sendo a variável que melhor prediz o abandono dos estudos.

Nicholson-Crotty, Birchmeier e Valentine (2009) alertam ainda que, devido a questôes de natureza étnico-racial, a maioria dos estudantes punidos mais intensamente por problemas de comportamento na escola, nos Estados Unidos, é negra. Segundo os autores, estes são suscetíveis a receberem punições mais severas se comparados à contraparte branca, pelo mesmo comportamento. Nessa esteira, os autores indicam que a suspensão escolar, como modo de lidar com os problemas de comportamento dos alunos, contribui para que adolescentes passem mais tempo na rua expostos às instituiçôes formais de controle, tais como a polícia, que podem apreendê-los por não estarem na escola em horário de aula, agravando a situação de vulnerabilidade em que se já encontram.

4) Associação entre bullying, problemas escolares e comportamento infracional na adolescência

A investigação desenvolvida por Chan e Chui (2013) evidenciou que comportamentos de bullying escolar se encontravam positivamente relacionados a comportamentos contrários à lei, especialmente roubo e delitos violentos, relação essa mediada por um baixo compromisso dos alunos com a escolarização. Wolke, Copeland, Angold e Costello (2013), em seu turno, identificaram o bullying como um indicador para vadiagem e consumo de drogas. 
Zaine, Reis e Padovani (2010), tendo por amostra adolescentes em cumprimento de medida socioeducativa, em uma cidade do interior paulista, constataram que todos os adolescentes investigados haviam se envolvido em episódios de bullying, como vítimas ou como agressores. Além disso, em relação aos agressores, verificou-se que as intimidações que praticavam não se limitavam aos colegas, mas incluíam adultos, indicando que a eficácia do modo agressivo de se relacionar na escola havia se expandido no sentido de abarcar a interação com outras pessoas, não somente os pares, e a outros contextos sociais além da escola.

A inserção em ambientes escolares violentos se associou ao risco aumentado de cometimento de infraçôes, conforme pesquisa desenvolvida por Egli et al. (2010). Uma estratégia de prevenção, nesse contexto, seria melhorar a organização escolar, visando a minimizar a exposição dos alunos às situações de violência (Beeck, Pauwels \& Put, 2012), uma vez que contextos escolares mais organizados estimulam a vinculação dos alunos à escola, o que exerce um efeito de proteção ao bullying e à prática de atos infracionais.

Wynne e Joo (2010) apresentaram alguns preditores do fenômeno bullying na escola: presença de gangues, intensa participação em atividades paraescolares, experiências prévias de vitimização, baixo desempenho e renda familiar alta. Argumentam que a presença de gangues na escola aumenta o risco de vitimização ou as chances de testemunhar situações de violência. A intensa participação em atividades paraescolares oportuniza a exposição dos jovens a situações vexatórias, tais como trotes entre colegas, além de incrementar a possibilidade de participação ou de observação de violência. Experiências prévias de vitimização podem colaborar para que os alunos se sintam rejeitados por colegas e professores, promovendo a desvinculação da escola mediante faltas às aulas e, ou, pelo isolamento social que os torna mais vulneráveis a sofrerem agressões. $\mathrm{O}$ baixo desempenho segue também nessa direção, considerando que os alunos nessa condição podem se sentir rejeitados, ficando isolados e mais propensos a serem vitimizados, dado também trazido por Lee (2013). Uma alta renda familiar se relaciona a situações de chantagem, furto e roubo. Todas as situações apresentadas agenciam a manifestação de bullying e, consequentemente, os efeitos associados a esse, que proporcionam ao surgimento de condutas contrárias à lei.

\section{5) A evasão escolar e a conduta infracional}

Os resultados obtidos por Shandra e Hogan (2012) indicam que os adolescentes com dificuldades de aprendizagem estão mais propensos à evasão e ao cometimento de atos infracionais. Para Zhang (2011), evasão escolar e envolvimento com a prática de delitos encontram-se ambos associados a múltiplas 
desvantagens, sendo estas, especialmente: dificuldades de aprendizagem, desorganização familiar e, ou, presença de histórico criminal na família e condição socioeconômica desfavorável. Além desses aspectos, Mallett (2010) e Dembo et al. (2012) sublinham também a presença de problemas de saúde mental do aluno e história de maus-tratos com passagem por serviços de proteção, baixa escolaridade dos responsáveis e consumo de substâncias psicoativas por parte desses.

Geib, Chapman, D’Amaddio e Grigorenko (2011) identificaram em seu estudo uma articulação sequencial entre dificuldades na escolarização, evasão escolar e prática de delitos. Contrariamente, vinculação escolar forte, segundo os dados encontrados por Chui e Chan (2012), funciona como importante fator de proteção à evasão e ao envolvimento em delitos de roubo e violência.

Investigando a relação entre desempenho escolar durante o período de internação e seus efeitos na reintegração dos adolescentes na comunidade e a reincidência infracional, Blomberg, Bales, Mann, Piquero e Berk (2011) observaram que os adolescentes que, durante a internação, realizavam aquisições escolares acima da média que tinham na escola regular se apresentavam mais propensos a ter uma melhor reinserção comunitária e escolar. As aquisições escolares durante o período de internação também se mostraram associadas a menores taxas de evasão escolar posterior e as de reincidência na prática de delitos, conforme estudo de Blomberg, Bales e Piquero (2012).

Hirschfield (2009), ao pesquisar os possíveis efeitos da passagem pelo Sistema de Justiça na experiência escolar de adolescentes, averiguou o incremento da evasão escolar, provavelmente devido à rotulação e à exclusão dos adolescentes no ambiente escolar, por conta do estigma gerado pelo rótulo de infrator. Os resultados também indicaram a aplicação de punições mais severas a esses alunos. Hipotetiza-se que isso possa gerar nos adolescentes infratores a sensação de injustiça e de raiva atrelada à escola, além de fomentar o processo de desvinculação e consequente abandono dos estudos.

\section{Discussão}

Com base nos resultados apresentados, deve-se considerar o fato de que, ao iniciar sua trajetória na escolarização, os alunos já acumulam diferentes aquisiçôes e déficits desenvolvimentais e de comportamento, relacionados ao convívio familiar, sendo que esses tendem a impactar a experiência escolar. Assim, variáveis pertinentes à família também necessitam ser consideradas quando se analisa a qualidade das experiências escolares, uma vez que podem tanto proteger quanto suscitar o surgimento de dificuldades de integração escolar, problemas de 
aprendizagem e vinculação (Bui, 2009; Huan et al., 2010; Kim \& Page, 2013; Sander et al., 2010; Ward et al., 2010).

Infere-se, portanto, que as experiências precoces, atreladas à vida em família, propiciam os elementos (as aquisições e, ou, dificuldades) que perpassam os processos de socialização experimentados em outros contextos sociais. Assim, uma boa qualidade nas experiências familiares pode favorecer a vinculação escolar e o bom desempenho bem como atenuar ou impedir a manifestação de problemas disciplinares e de conduta infracional, sendo que o contrário também é confirmado. Desse modo, a compreensão das relações existentes entre a escolarização e a conduta infracional nos adolescentes precisa considerar, em alguma medida, aspectos atinentes à família, pois, embora seus efeitos sejam indiretos, eles modulam as condições que favorecem ou não a qualidade da experiência educacional. A importância das variáveis familiares, apesar de menor, não pode ser menosprezada.

De todo modo, pode-se também considerar que, independentemente das experiências que antecedem a entrada na escola, o que se vivencia no cotidiano escolar per si impacta o desenvolvimento das crianças e dos adolescentes. Numa perspectiva interacional, as relaçôes nesse ambiente funcionam como fator de risco ou como fator de proteção a problemas no processo de socialização, inclusive à delinquência juvenil. Os estudos revisados permitiram compreender que o estabelecimento de um bom relacionamento com professores e com colegas, no contexto escolar, representa um importante mecanismo à vinculação escolar e que os adolescentes em conflito com a lei apresentam, em geral, muitas dificuldades nesse plano (Ashkar \& Kenny, 2009; Sander et al., 2010).

LeBlanc $(2003,2006)$ oferece alguns subsídios para o esclarecimento dessa relação explicando que, em termos dinâmicos, a existência de um bom relacionamento com os professores é importante porque representa para o aluno o sentimento de segurança de ter ajuda, no plano acadêmico, sempre que necessário. Consequentemente, a oferta de ajuda por parte dos professores, nos momentos de dificuldade, pode ser interpretada pelos alunos como indicador de interesse e de estima/apreço. Tal percepção, em seu turno, reforça a comunicação, caracterizada por diálogos entre professores e alunos, não somente no plano dos conteúdos escolares, mas também no que concerne à oferta de conselhos, elogios e incentivos por parte dos professores. A proximidade relacional, pautada em respeito recíproco, viabiliza o vínculo escolar mediante o aumento do investimento em atividades escolares e do compromisso escolar, e diminui a necessidade de aplicação de sanções (punições), porque a adesão às regras escolares, veiculadas pelas autoridades (incluindo os professores), faz-se naturalmente. 
Considerando que a qualidade da relação com professores ultrapassa os limites de uma interação diádica, gerando repercussões em outros aspectos da vida escolar dos alunos, essa dimensão deve se constituir em um objeto a ser considerado em outras pesquisas bem como se transformar em um dos focos no planejamento de intervenções de prevenção e de reinserção escolar de adolescentes em conflito com a lei.

$\mathrm{Na}$ literatura, destaca-se ainda o dado de que a aplicação de punições muito rígidas pelas autoridades escolares contribui para a desvinculação dos alunos, embora pareçam gerar efeito positivo a curto prazo, em termos de controle do comportamento (disciplina). A longo prazo, as sanções produzem um afastamento da vida escolar, especialmente nos estudantes que apresentam dificuldades, e, nessa esteira, favorecem seu engajamento em atividades fora da escola e, dentro disso, oferecem-se as atividades contrárias à lei (Kirk \& Sampson, 2013; NicholsonCrotty et al., 2009; Sullivan et al., 2010). Os estudos analisados denotaram que as puniçóes escolares constituem um tema relevante a ser considerado no tocante à gênese da desadaptação dos alunos e do cometimento de atos infracionais, pois um tratamento mais severo não representa somente uma reação das autoridades escolares diante das infrações disciplinares dos alunos, mas envolve, igualmente, os critérios para julgar o que e quem deve ser punido e a aplicação das punições pelas autoridades da instituição, o que pode ocasionar discrepâncias nas atuaçôes ou injustiças.

Isto é, alguns estudantes podem ser mais vulneráveis que outros nessas situações, devido, por exemplo, a determinados preconceitos e rotulações estabelecidas previamente, o que é passível de acontecer com os adolescentes infratores. Assim, os métodos disciplinares diante de comportamentos de desobediência às regras escolares necessitam ser examinados criteriosamente para que os adolescentes com comportamento considerado problemático recebam serviços adequados, e não somente sanções, tendo em mente que estas podem favorecer o processo de desvinculação escolar e, com isso, amplificar o comportamento de desobediência às regras escolares. Ademais, as sançōes escolares são, em geral, percebidas como injustas, especialmente por adolescentes que apresentam dificuldades de adaptação escolar; assim, o sentimento injustiça suscitado aumenta o risco de evasão escolar e a suscetibilidade ao envolvimento infracional (Kirk \& Sampson, 2013).

Os apontamentos de Sullivan et al. (2010) alertam para o fato de, nas escolas americanas, em especial, se estar utilizando o Sistema de Justiça no enfrentamento de problemas disciplinares, desconsiderando os efeitos negativos de tal procedimento no desempenho escolar e na vinculação dos alunos. Por conta disso, medidas alternativas de regulação do comportamento na escola precisam 
ser consideradas, no sentido de se evitar a submissão à autoridade judicial alunos cujos comportamentos não constituam atos infracionais.

As produções revisadas também evidenciaram que o bullying tem despertado a atenção em razão dos seus altos índices de incidência no ambiente escolar e pela gravidade de suas consequências aos alunos envolvidos (Beeck et al., 2012; Chan \& Chui, 2013; Egli et al., 2010; Lee, 2013; Wynne \& Joo, 2010; Wolke et al., 2013; Zaine et al., 2010). Resumidamente, os estudos apontam para a necessidade de se examinar a influência das dinâmicas institucionais e socioculturais que mobilizam e governam alguns dos principais aspectos da vitimização entre pares na escola, pois a participação ou a exposição à violência no contexto escolar exerce impacto sobre a conduta dos estudantes, podendo induzir respostas igualmente violentas dentro e fora dos muros das escolas, o que aumenta o risco de envolvimento em atos contrários à lei.

Para finalizar, tornou-se notória, com base nos estudos apresentados, a centralidade da variável evasão escolar nos achados concernindo adolescentes em conflito com a lei, uma vez que essa se constitui em um dos preditores mais importantes da conduta infracional na adolescência, além de encontrarse associada ao desenvolvimento de outros problemas, tais como a redução das chances para obtenção de sucesso profissional em profissões que exigem maior preparo e qualificação (Blomberg et al., 2011; Blomberg et al., 2012; Chui \& Chan, 2012; Dembo et al., 2012; Geib et al., 2011; Hirschfield, 2009; Mallett, 2010; Shandra \& Hogan, 2012; Zhang, 2011). Nessa direção, Archambault, Janosz, Fallu e Pagani (2009) esclarecem que a desvinculação escolar se caracteriza como um processo gradual, sendo a evasão a indicação mais grave da existência de um desajuste entre as necessidades dos alunos e as expectativas e demandas sobre eles depositadas. Portanto uma experiência escolar marcada por insucessos ou muitos aspectos negativos certamente colabora para que a escola perca a atratividade e para que o abandono dos estudos seja legitimado como estratégia para se procurar outras experiências/oportunidades que podem oferecer maiores chances para o sucesso, mesmo que seja por vias não convencionais, como no caso da prática de atos ilícitos. A evasão, assim caracterizada, ocorre, na maioria das vezes, quando já não existe ponto de identificação entre o estudante e a instituição escolar.

O afastamento da escola configura-se, desse modo, em um marco importante, seja no tocante ao início de uma trajetória de envolvimento infracional, seja como ponto de viragem no que respeita a um agravamento nesta, com a intensificação do engajamento infracional, uma vez que os adolescentes, com a desvinculação escolar, tornam-se mais vulneráveis pelo tempo ocioso sem supervisão e, no período sem atividades, pela possibilidade aumentada de ligação a pares que 
apresentem problemas de comportamento ou conduta infracional. Ademais, sobre os adolescentes evadidos que não se integram ao mercado de trabalho, parece incidir uma maior vigilância das agências oficiais de controle (polícia), o que incrementa as chances de serem pegos em comportamentos de desobediência às normas de convivência social e infracionais e, por isso, apreendidos, gerando um ciclo de consequências negativas que pode piorar a situação educacional desses jovens (Bazon et al., 2011). Isso resulta tanto em prejuízos pessoais para o adolescente, que fica impossibilitado de aproveitar os benefícios que a escolarização poderia lhe oferecer, quanto em prejuízos sociais, pois a sociedade é atingida negativamente pela existência de um segmento com baixo nível de escolarização e em alto risco de cometimento de delitos.

Obviamente, é preciso considerar que a frequência escolar agencia fatores de proteção ao desenvolvimento na adolescência, desde que estejam inseridos em contextos educacionais cujo funcionamento seja regido por determinados parâmetros, tais como a oferta de uma rotina minimamente convencional, adequação das regras e justa aplicação de medidas disciplinares, além da oferta de ajuda na medida das necessidades de aprendizagem de cada aluno e de estímulo ao fortalecimento dos relacionamentos humanos (Janosz \& Leblanc, 1999). Assim, evidencia-se a necessidade de se enfocar o problema da evasão sob uma perspectiva de intervenção precoce, em contingência aos primeiros sinais de desadaptação apresentados pelos alunos, de modo a atenuar ou interromper o processo de desenvolvimento das dificuldades manifestas nesse ambiente. De maneira similar, a melhoria das condições de reinserção escolar de adolescentes com passagem pelo Sistema de Justiça se faz necessária pelo fato de esta representar proteção à experiência de novos fracassos ou às situações de isolamento, rotulação e não aprendizagem, por ocasião da reinserção no ensino regular.

\section{Considerações finais}

Os estudos revisados permitiram a identificação de uma produção científica diversificada acerca da relação entre escolarização e conduta infracional, sinalizando o interesse de pesquisadores por essa temática, em diferentes realidades socioculturais. Em síntese, os resultados obtidos por meio das análises efetuadas para o fim da sistematização da literatura colocaram em destaque, de um lado, a existência de fatores extraescolares associados à produção da conduta infracional, mas que atuam mediados pelo impacto negativo que produzem (ou que podem produzir) no processo de escolarização. Dentro disso, sublinhou-se que a desadaptação escolar se associa à conduta infracional e tem relação com experiências prévias ao ingresso do aluno na escola, referente à vida em família. 
Contudo, nas investigações revisadas, sobressaíram-se os apontamentos sobre o impacto de variáveis escolares (inerentes à vida do aluno na escola): sanções (punições), relacionamento negativo com professores e colegas, exposição à violência escolar e evasão.

O conjunto dos trabalhos analisados evidenciou a complexidade da interface existente entre as categorias temáticas elaboradas, considerando-se os contextos envolvidos (família e escola) e as características dos diferentes indivíduos em interação (crianças, adolescentes, adultos, pais, professores, entre outros). A natureza direta e indireta do impacto das variáveis escolares sobre a conduta dos alunos, a multiplicidade de configurações decorrentes dessas interfaces também denota a relevância de se considerar a natureza dinâmica, intercambiante, entre as trajetórias de desenvolvimento pessoal, social e escolar dos estudantes, para a compreensão do comportamento infracional na adolescência.

Cumpre ressaltar que a maioria das pesquisas analisadas decorreu de estudos transversais, cujo alcance metodológico limita as possibilidades de generalização dos resultados e a possibilidade do estabelecimento de relações de causalidade entre as variáveis. Assim, apesar das contribuições oferecidas às proposições teóricas e das várias pistas sinalizadas ao planejamento e à realização de intervençōes de prevenção e de tratamento do problema em foco (comportamento infracional na adolescência), estas devem ser tomadas com cautela, uma vez que existem lacunas a serem preenchidas por futuras investigaçôes. Uma alternativa possível ao atendimento dessas questóes é a realização de estudos com delineamento longitudinal, pelo fato de esses possibilitarem a obtenção de dados mais precisos no tocante à existência de relações causais entre as variáveis investigadas, bem como por permitirem apreender a complexidade das relações entre as variáveis em estudo, as formas de interação e os efeitos recíprocos ao longo do tempo. Também se identificou a necessidade de realização de mais estudos de abordagem qualitativa, com vistas à obtenção de dados contextualizadas e atinentes aos processos subjetivos experimentados pelos adolescentes infratores, no tocante à vida escolar.

Localizou-se ainda um predomínio de estudos internacionais, realizados principalmente nos Estados Unidos, em contraste à escassez de estudos brasileiros, embora se tenha realizado levantamento em bases bibliográficas nacionais. Depreende-se, portanto, a necessidade de realização de mais investigações na realidade nacional, seja porque o problema do envolvimento de adolescentes com a prática de atos infracionais é significativo em nossa realidade, seja porque se considera que esse apresenta características contextuais e culturais específicas, que em alguns aspectos a diferenciam substancialmente da de outros países. Tais estudos poderão fornecer subsídios consistentes ao ajustamento da organização do 
sistema educacional brasileiro que respaldem propostas de prevenção primária e secundária da problemática relativa ao engajamento infracional na adolescência, em nossa realidade.

\section{Referências}

Archambault, I., Janosz, M., Fallu, J. S. \& Pagani, L. S. (2009). Student engagement and its relationship with early high school dropout. Journal of Adolescence, 32 (3), 651-670.

Ashkar, P. \& Kenny, D. T. (2009). Young offenders' perceptions of school: an ecological analysis. Psychiatry Psychology and Law, 16 (3), 355-368.

Bazon, M. R., Komatsu, A. V., Panosso, I. R. \& Estevão, R. (2011). Adolescentes em conflito com a lei, padrões de comportamento infracional e trajetória da conduta delituosa: um modelo explicativo na perspectiva desenvolvimental. Revista Brasileira Adolescência e Conflitualidade, 5 (2), 59-87.

Beeck, H. O., Pauwels, L. J. R. \& Put, J. (2012). Schools, strain and offending: Testing a school contextual version of General Strain Theory. European Journal of Criminology, 9 (1), 52-72.

Blomberg, T. G., Bales, W. D., Mann, K., Piquero, A. R. \& Berk, R. A. (2011). Incarceration, education and transition from delinquency. Journal of Criminal Justice, 39 (4), 355-365.

Blomberg, T. G., Bales, W. D. \& Piquero, A. R. (2012). Is educational achievement a turning point for incarcerated delinquents across race and sex? Journal of Youth Adolescence, 41 (2), 202-216.

Bui, H. N. (2009). Parent-child conflicts, school troubles, and differences in delinquency across immigration generations. Crime \& Delinquency, 55 (3), 412-441.

Caldwell, R. M., Wiebe, R. P. \& Cleveland, H. H. (2006). The influence of future certainty and contextual factors on delinquent behavior and school adjustment among African American adolescents. Journal of Youth and Adolescence, 35 (4), 591-602.

Chan, H. C. O. \& Chui, W. H. (2013). Social bonds and school bullying: A study of Macanese male adolescents on bullying perpetration and peer victimization. Child \& Youth Care Forum, 42 (6), 599-616. 
Chui, W. H. \& Chan, H. C. O. (2012). An empirical investigation of social bonds and juvenile delinquency in Hong Kong. Child \& Youth Care Forum, 41 (4), 371-386.

Conselho Nacional de Justiça (2012). Panorama nacional: a execução das medidas socioeducativas de internação. Recuperado a partir de http://www.cnj.jus.br / images/pesquisas-judiciarias/Publicacoes/panorama_nacional_doj_web.pdf.

Dembo, R., Briones-Robinson, R., Barrett, K., Winters, K. C., Ungaro, R., Karas, L., Belenko, S. (2012). Psychosocial problems among truant youth: a multi-group, exploratory structural equation modeling analysis. Journal of Child \& Adolescent Substance Abuse, 21 (5), 440-465.

Egli, N., Vettenburg, N., Savoie, J., Lucia, S., Gavray, C., Zeman, K. (2010). Belgium, Canada and Switzerland: are there differences in the contributions of selected variables on self-reported property-related and violent delinquency? European Journal on Criminal Policy and Research, 16 (3), 145-166.

Frías-Armenta, M., López-Escobar, A. E. \& Díaz-Méndez, S. G. (2003). Predictores de la conducta antisocial juvenil: un modelo ecológico. Estudios de Psicología, 8 (1), 15-24.

Geib, C. F., Chapman, J. F., D’Amaddio, A. H. \& Grigorenko, E. L. (2011). The education of juveniles in detention: policy considerations and infrastructure development. Learning and Individual Differences, 21 (1), 3-11.

Hirschfield, P. (2009). Another way out: the impact of juvenile arrests on high school dropout. Sociology of Education, 82 (4), 368-393.

Huan, V. S., Ang, R. P. \& Lim, H. Y. N. (2010). The influence of father criminality on juvenile recidivism testing for delinquent behaviors as a mediator. International Journal of Offender Therapy and Comparative Criminology, 54 (4), 566-580.

Janosz, M. \& LeBlanc, M. (1999). Abandono escolar na adolescencia: factores comuns e trajectórias múltiplas. Revista Portuguesa de Pedagogia, 34 (1-3), 341403.

Kim, H.Y. \& Page, T. (2013). Emotional bonds with parents, emotion regulation, and school-related behavior problems among elementary school truants. Journal of Child and Family Studies, 22 (6), 869-878. 
Kirk, D. S. \& Sampson, R. J. (2013). Juvenile arrest and collateral educational damage in the transition to adulthood. Sociology of Education, 86 (1), 36-62.

LeBlanc, M. (2003). Traité de criminologie empirique (3th ed.). Montréal: Université de Montréal Press.

LeBlanc, M. (2006). Self-control and social control of deviant behavior in context: development and interactions along the life course. In P. O. H. Wikstrom \& R. J. Sampson (Orgs.). The explanation of crime context, mechanisms, and development. (pp. 124-151). New York: Cambridge University Press.

Lee, J. (2013). A cross-lagged longitudinal study of relations between academicachievement and Korean adolescent delinquency. Health Education Journal, 72 (5), 555-563.

Liljeberg, J. F., Eklund, J. M., Fritz, M. V. \& Klinteberg, B. (2011). Poor school bonding and delinquency over time: bidirectional effects and sex differences. Journal of Adolescence, 34 (1), 1-9.

Mallett, C. A. (2010). An at-risk profile of probation supervised youthful offenders in a rural, midwest county: significant gender and race differences. Juvenile and Family Court Journal, 61 (3), 1-12.

Maschia, T., Hatcher, S. S., Schwalbe, C. S. \& Rosato, N. S. (2008). Mapping the social service pathways of youth to and through the juvenile justice system: a comprehensive review. Children and Youth Services Review, 30 (12), 13761385 .

Nicholson-Crotty, S., Birchmeier, Z. \& Valentine, D. (2009). Exploring the impact of school discipline on racial disproportion in the juvenile justice system. Social Science Quarterly, 90 (4), 1003-1018.

Sander, J. B., Sharkey, J. D., Olivarri, R., Tanigawa, D. A. \& Mauseth, T. (2010). A qualitative study of juvenile offenders, student engagement, and interpersonal relationships: Implications for research directions and preventionist approaches. Journal of Educational and Psychological Consultation, 20 (4), 288-315.

Shandra, C. L. \& Hogan, D. P. (2012). Delinquency among adolescents with disabilities. Child Indicators Research, 5 (4), 771-788.

Silveira, M. A. S., Maruschi, M. C. \& Bazon, M. R. (2012). Risk and protection for adolescents engaged in practices of offensive conduct. Revista Brasileira de Crescimento e Desenvolvimento Humano, 22 (3), 348-357. 
Sullivan, C. J., Dollard, N., Sellers, B. \& Mayo, J. (2010). Rebalancing response to school-based offenses: a civil citation program. Youth Violence and Juvenile Justice, 8 (4), 279-294.

Ward, A. K., Day, D. M., Bevc, I., Sun, Y., Rosenthal, J. S. \& Duchesne, T. (2010). Criminal trajectories and risk factors in a Canadian sample of offenders. Criminal Justice and Behavior, 37 (11), 1278-1300.

Wolke, D., Copeland, W. E., Angold, A. \& Costello, E. J. (2013). Impact of bullying in childhood on adult health, wealth, crime, and social outcomes. Psychological Science, 24 (10), 1958-1970.

Wynne, S. L. \& Joo, H. J. (2010). Predictors of school victimization: individual, familial, and school factors. Crime \& Delinquency, 37 (3), 458-488.

Zaine, I., Reis, M. J. D. \& Padovani, R. C. (2010). Comportamentos de bullying e conflito com a lei. Estudos de Psicologia, 27 (3), 375-382.

Zhang, L. (2011). Family, school and friends: correlates of Canadian youth outcomes. Child Indicators Research, 3 (4), 467-498. 